\title{
AVALIAÇÃO MICROBIOLÓGICA DE CARNE MOÍDA E QUIBE CRU COMERCIALIZADA EM UMA CIDADE DO OESTE PAULISTA
}

\author{
Isabelle Bueno Lamas, Letícia Gonçalves, Osemar Linhares Junior, Lizziane Kretli Winkelstroter Eller \\ Universidade do Oeste Paulista - UNOESTE, Presidente Prudente, SP. e-mail: lizzianekretli@gmail.com
}

\begin{abstract}
RESUMO
O objetivo desse trabalho foi avaliar a qualidade microbiológica da carne moída e quibe cru comercializados em Presidente Prudente-SP. Foram coletados 30 amostras de carne moída e quibe cru para a quantificação de coliformes totais e termotolerantes, aeróbios mesófilos, bolores e leveduras. Foi aplicado um formulário para cada estabelecimento onde foram observadas condições higiênicas sanitárias e adequações do ambiente para o manuseio da carne. Foram observadas condições higiênicas insatisfatórias devido a ausência de paramentação dos funcionários e a presença de animais ou insetos no ambiente. Foram notadas altas contagens para aeróbios mesófilos, bolores e leveduras e coliformes totais. Coliformes termotolerantes estava presente em várias amostras de carne moída e quibe cru, entretanto, todos os valores estavam abaixo dos parâmetros estabelecidos pela legislação. Os dados despertam a atenção em relação a Saúde Pública uma vez que as falhas das condições higiênico-sanitárias podem representar um risco potencial à saúde dos consumidores.
\end{abstract}

Palavras-chave: Contaminação, coliformes, mesófilos, bolores, leveduras.

\section{MICROBIOLOGICAL EVALUATION OF GROUND MEAT AND RAW KIBBEH MARKETED IN A CITY IN THE WEST OF SÃO PAULO}

\begin{abstract}
The objective was to evaluate the microbiological quality of ground beef and raw kibbe marketed in Presidente Prudente-SP. Thirty samples of ground beef and quibe croup were collected for quantification of total and thermotolerant coliforms, aerobic mesophiles, molds and yeasts. A form was applied to each establishment where hygienic sanitary conditions and environmental adjustments were observed for meat handling. Unsatisfactory hygienic conditions were observed due to the absence of staffing and the presence of animals or insects in the environment. It was noted high counts for mesophyll aerobes, molds and yeasts and total coliforms. Thermotolerant coliforms were present in several samples of ground beef and raw kibbe, however, all values were below the parameter established by the legislation. The data raise the attention in relation to Public Health since the failures of hygienic-sanitary conditions can represent a potential risk to the health of the consumers.
\end{abstract}

Keywords: Contamination, coliforms, mesophiles, molds, yeast.

\section{INTRODUÇÃO}

O Brasil é considerado o segundo maior consumidor de carne bovina no mundo'. Os brasileiros consumiram cerca de $7.982 \mathrm{mil}$ toneladas de carne apenas no ano de $2014^{2}$. Este dado corresponde a um consumo diário per capita de 63,2/g/dia (totalizando cerca de $23 \mathrm{~kg} /$ percapita/ano), perdendo apenas para o feijão (182,9g/dia) e o arroz (160,3g/dia) ${ }^{2}$.

Por ser rica em nutrientes, a carne se torna facilmente em um meio de cultura para proliferação de bactérias patogênicas 
deterioradoras do produto, causando assim uma das principais fontes de toxinfecções alimentares. A contaminação microbiana no processo de abate pode ocorrer principalmente devido ao manuseio incorreto, local e armazenamento inapropriado ${ }^{3}$.

O transporte da carne também pode oferecer risco de contaminações principalmente devido a inadequação dos processos de refrigeração, a subdivisão das peças, processos de congelamento/descongelamento, exposição ao ar, ao ambiente, técnicas higiênicas inadequadas, embalagem e armazenamento ${ }^{4}$. Nos açougues, os principais riscos oferecidos estão relacionados a condições higiênicas sanitárias ${ }^{5}$. Por conta destes riscos, há algumas condições higiênicas sanitárias que os estabelecimentos devem tomar cuidado. É de responsabilidade dos açougues manterem toda a carne sob refrigeração, seus funcionários devem estar uniformizados com jaleco, calça comprida, touca descartável, avental, bota de borracha de cor branca, luva de malha de aço (própria da desossa) e com os cabelos, barba e unhas sempre limpos e aparados. Qualquer funcionário que esteja portando alguma doença transmissível não deve ter acesso ao açougue e o estabelecimento deve ter um responsável técnico para poder observar se todas as etapas/cuidados estão sendo seguidos conforme a legislação.

Algumas práticas realizadas no açougue, como a moagem, incluem riscos de contaminações das carnes, uma vez que são utilizados cortes com tecidos gordurosos que podem conter nódulos linfáticos com microrganismos em seu interior. Além disso, após o processo de moagem, mesmo mantida sob refrigeração, microrganismos deteriorantes podem continuar a desenvolver com mais facilidade devido a maior exposição da área superficial ${ }^{6}$.

A segurança alimentar é uma grande preocupação mundial. As doenças transmitidas por alimentos (DTA's) são responsáveis por danos à saúde do consumidor, além de resultar em prejuízos dos sistemas de saúde e da própria sociedade. Vários surtos já foram relacionados com a ingestão de alimentos contaminados. Dentre os alimentos envolvidos em surtos alimentares podemos citar: ovos e produtos à base de ovo cru, doces e sobremesas, água, carne bovina in natura, processados e miúdos, leite e derivados, carne de frango processados e miúdos. Entre os agentes etiológicos, os mais comumente identificados são as bactérias como
Salmonella spp, Staphylococcus aureus, Escherichia coli, Bacillus cereus e Clostridium perfringens, os vírus Hepatite A e Rotavírus e os parasitas Giardia, Cryptosporidium spp e Toxoplasma gondii ${ }^{7,8}$.

Segundo a Vigilância Sanitária os principais fatores relacionados com a contaminação de alimentos por agentes patógenos são: ingredientes crus contaminados; pessoas infectadas; práticas inadequadas de manipulação; limpeza e desinfecção deficiente dos equipamentos; alimentos sem procedência; alimentos contaminados durante a preparação; recipientes contendo contaminantes tóxicos; plantas tóxicas tomadas por comestíveis; aditivos acidentais; aditivos intencionais; saneamento deficiente. Além destes, outros fatores podem favorecer a proliferação destes agentes como a preparação com excessiva antecipação; alimentos deixados à temperatura ambiente; alimentos esfriados em panelas grandes; inadequada conservação a quente; descongelamento inadequado; preparação de quantidades excessivas $^{1,9}$.

Além destes pontos estabelecidos pela Vigilância Sanitária, outro fator que pode ser determinante para a compra de carne contaminada é a procedência da mesma. Sabendo-se que os açougues clandestinos possuem atividade no mercado, eles vão ser responsáveis pela fabricação e distribuição de produtos com a finalidade de trazer um preço bom e competitivo para o comércio, deixando de lado as Boas Práticas de Fabricação e trazendo risco para o consumidor ${ }^{10}$.

Diante desse contexto, fica demonstrado que a segurança alimentar deve ser um requisito fundamental ao longo de toda cadeia produtiva da carne, desde o abate até a distribuição final ao consumidor. Devido à escassez de dados referentes à qualidade microbiológica da carne moída e as condições atuais do fornecimento deste alimento nos estabelecimentos espalhados em diversos pontos em uma cidade do oeste paulista fica demonstrado à importância de se avaliar a qualidade microbiológica da carne moída e do quibe cru, uma vez que a falha nas condições higiênico-sanitárias pode representar um risco potencial à saúde dos consumidores.

O objetivo deste trabalho foi avaliar a qualidade microbiológica da carne moída e quibe cru comercializada em uma cidade do Oeste Paulista por meio da quantificação de aeróbios mesófilos, bolores/leveduras e coliformes totais e 
termotolerantes. Além disso, foram observadas as condições higiênico-sanitária dos funcionários e instalações por meio de formulário de pontos críticos.

\section{METODOLOGIA}

Amostras

Foram obtidas 15 amostras de carne moída e 15 amostras da preparação de quibe cru de diferentes açougues e estabelecimentos, destes foram 2 açougues, 2 restaurantes e 26 mercados de Presidente Prudente-SP. Para a análise microbiológica, foram coletados cerca de $100 \mathrm{~g}$ de cada preparação, sendo armazenado em condições assépticas, dentro de sacos plásticos esterilizados e transportado até o laboratório de microbiologia da Universidade do Oeste Paulista para a realização das análises. As amostras foram analisadas de acordo com os padrões microbiológicos vigentes, na Resolução RDC $n^{\circ} 12$ de 02 de janeiro de 2001 da ANVISA ${ }^{11}$.

Quantificação de coliformes totais, aeróbios mesófilos, bolores e leveduras

Para a quantificação dos microrganismos foram utilizados 25 gramas de cada amostra de carne moída, em seguida o material foi diluído em $225 \mathrm{ml}$ de água peptonada a 0,1\% esterilizada e posteriormente homogeneizados, obtendo-se assim a diluição de $10^{-1}$. A partir dessa diluição, foram feitas diluições em série até a obtenção da diluição $10^{-5}$. A determinação de aeróbios mesófilos consistiu na semeadura em ágar padrão de contagem (PCA) pela técnica de semeadura em superfície. As placas foram incubadas por $48 \mathrm{~h}$ a $37^{\circ} \mathrm{C}$. Para a quantificação de bolores e leveduras, as mesmas diluições foram semeadas na superfície de ágar de batata dextrose (PDA) e em seguida incubadas por $72 \mathrm{~h}$ a $25^{\circ} \mathrm{C}^{12,13}$.

As diluições $\left(10^{-1}\right.$ a $\left.10^{-3}\right)$ foram utilizadas para verificar a presença de coliformes totais e termotolerantes. Uma alíquota de $1 \mathrm{~mL}$ de cada diluição $\left(10^{-1} 10^{-2} 10^{-3}\right)$ foi transferida para três tubos com $5 \mathrm{~mL}$ de caldo (VB) verde brilhante $2 \%$ e caldo E.C. Echerichia coli contendo tubos de
Durhan invertidos para o crescimento de coliformes totais e termotolerantes. O caldo VB foi incubado a $37^{\circ} \mathrm{C}$ e o caldo E. C. deixados em banho-maria de 44,5 a $45^{\circ} \mathrm{C}$ durante $24 \mathrm{~h}$. A positividade do teste foi observada pela produção de gás no interior dos tubos de Durhan. O número de coliformes totais e termotolerantes foram obtidos na tabela de Número Mais Provável (NMP), baseado no número de tubos positivos do caldo (VB) verde brilhante e de caldo(EC)Escherichia coli respectivamente, sendo os resultados expressos em NMP/100 ${ }^{12,13}$.

Os experimentos foram realizados em triplicatas e os resultados foram expressos em logarítmico das unidades formadoras de colônias por grama de alimento (Log UFC/g).

Formulário de avaliação de condições higiênicassanitárias

Além das análises microbiológicas foi aplicado um formulário para avaliar se os estabelecimentos atendem os requisitos de conservação e higiene de onde é feita a manipulação da carne, se todos os funcionários cumprem com os paramentos de higiene pessoal, no momento da compra do produto ${ }^{14,15}$.

Análise dos dados

Foi realizada a análise estatística utilizando o programa Graphprism $5.0^{\circledR}$ e os resultados submetidos a análise de variância (ANOVA) seguido de teste a posteriori de comparações múltiplas de Tukey. Foi considerado o nível de significância $p<0,05$.

\section{RESULTADOS}

Em relação a carne moída foi observado que os valores de aeróbios mesófilos ficaram compreendidos de 3,33 $\pm 0,04$ a 5,43 $\pm 0,01$ log de UFC/g e para o quibe cru foi de $3,96 \pm 0,01$ a 5,32 $\pm 0,02$ log de UFC/g (Tabela 1). Os estabelecimentos C e I apresentaram o menor nível de contaminação para este microrganismo $(p<0,05)$ em amostras respectivamente, de carne moída e quibe cru. 
Tabela 1. Quantificação de aeróbios mesófilos, bolores e leveduras, coliformes totais e termotolerantes, Escherichia coli $(\mathrm{EC})$ em amostras de carne moída e quibe cru, comercializados na cidade de Presidente Prudente-SP.

\begin{tabular}{ccccll}
\hline $\begin{array}{c}\text { Local } \\
\text { de } \\
\text { coleta }\end{array}$ & $\begin{array}{c}\text { Tipo } \\
\text { Amostra }\end{array}$ & $\begin{array}{c}\text { Aeróbios } \\
\text { mesófilos } \\
\text { (logUFC/g) }\end{array}$ & $\begin{array}{c}\text { Bolores e } \\
\text { leveduras } \\
\text { (UFC/g) }\end{array}$ & $\begin{array}{l}\text { Coliformes } \\
\text { totais } \\
\text { (NMP/g) }\end{array}$ & $\begin{array}{l}\text { Coliformes } \\
\text { termotolerantes } \\
\text { (NMP/g) }\end{array}$ \\
\hline A & Carne & $5,28 \pm 0,07$ & $*$ & $>110$ & 2,3 \\
A & Carne & $5,40 \pm 0,07$ & $*$ & $>110$ & 2,3 \\
A & Carne & $5,34 \pm 0,01$ & $*$ & $>110$ & 15 \\
B & Carne & $5,05 \pm 0,01$ & $3,00 \pm 0,14$ & $>110$ & $<0,03$ \\
B & Carne & $4,36 \pm 0,03$ & $3,21 \pm 0,05$ & $>110$ & $<0,03$ \\
B & Carne & $4,48 \pm 0,08$ & $3,05 \pm 0,21$ & $>110$ & $<0,03$ \\
C & Carne & $4,00 \pm 0,03$ & $3,09 \pm 0,02$ & $<0,03$ & $<0,03$ \\
C & Carne & $3,33 \pm 0,04$ & $3,11 \pm 0,16$ & 24 & $<0,03$ \\
C & Carne & $3,42 \pm 0,24$ & $3,21 \pm 0,01$ & $<0,03$ & $<0,03$ \\
D & Carne & $4,32 \pm 0,18$ & $3,76 \pm 0,07$ & 46 & 9,3 \\
D & Carne & $4,96 \pm 0,01$ & $3,66 \pm 0,22$ & 11 & 15 \\
D & Carne & $5,03 \pm 0,00$ & $4,18 \pm 0,17$ & $>110$ & 2,9 \\
E & Carne & $5,29 \pm 0,00$ & $3,74 \pm 0,01$ & $>110$ & 11 \\
E & Carne & $5,43 \pm 0,01$ & $4,06 \pm 0,16$ & 5,2 & 11 \\
E & Carne & $5,29 \pm 0,01$ & $3,89 \pm 0,12$ & $>110$ & 4,6 \\
A & Quibe & $5,32 \pm 0,02$ & $3,91 \pm 0,10$ & 11 & 7,5 \\
A & Quibe & $5,11 \pm 0,05$ & $4,04 \pm 0,00$ & 11 & 2,3 \\
A & Quibe & $5,21 \pm 0,02$ & $3,92 \pm 0,09$ & 11 & 2,3 \\
F & Quibe & $5,19 \pm 0,00$ & $3,95 \pm 0,07$ & 11 & 15 \\
F & Quibe & $5,15 \pm 0,00$ & $4,08 \pm 0,10$ & $>110$ & $>110$ \\
F & Quibe & $5,19 \pm 0,02$ & $4,18 \pm 0,12$ & 11 & 11 \\
G & Quibe & $5,15 \pm 0,02$ & $3,83 \pm 0,14$ & 24 & $<0,03$ \\
G & Quibe & $5,16 \pm 0,02$ & $3,98 \pm 0,02$ & 11 & $<0,03$ \\
G & Quibe & $5,01 \pm 0,01$ & $3,84 \pm 0,11$ & 46 & $<0,03$ \\
H & Quibe & $4,93 \pm 0,00$ & $3,12 \pm 0,11$ & 46 & 2,3 \\
H & Quibe & $4,92 \pm 0,01$ & $3,08 \pm 0,12$ & 46 & 2,3 \\
H & Quibe & $4,59 \pm 0,06$ & $3,00 \pm 0,00$ & 11 & 2,3 \\
I & Quibe & $4,49 \pm 0,01$ & $2,38 \pm 0,55$ & 9,3 & $<0,03$ \\
I & Quibe & $3,96 \pm 0,01$ & $2,47 \pm 0,00$ & 4,3 & $<0,03$ \\
I & Quibe & $4,12 \pm 0,49$ & $2,38 \pm 0,12$ & 2,3 & $<0,03$ \\
\hline
\end{tabular}

*Valor abaixo do limite de detecção $<30$ UFC/g

Os resultados de bolores e leveduras ficaram compreendidos entre $3,00 \pm 0,14 a 4,18$ $\pm 0,17$ log de UFC/g para carne moída e 3,00 $\pm 0,00$ a $4,18 \pm 0,12$ log de UFC/g para o quibe cru. Apenas os resultados encontrados nas amostras de carne moída dos estabelecimentos $B$ versus $C$ e $D$ versus $E$ não foram significativamente diferentes $(p>0,05)$. Nas amostras de quibe cru não foram encontrados resultados significativamente diferentes entre estabelecimento $F$ versus $G$ e A versus $G(p>0,05)$. Neste trabalho também foi observado condições higiênico sanitárias dos funcionários e do estabelecimento. Dentre os itens que foram avaliados, destaca-se os resultados de não conformidade com os parâmetros estabelecidos pela legislação como: os funcionários não faziam o correto uso da uniformização ou o uso correto de alguns EPIs (90\%), funcionário utilizando barba e/ou bigode, e adorno como anéis, pulseiras, colares, até a relógios (100\%) e utensílios sujos ou com péssimo estado de conservação (90\%). Porém, podemos destacar bons resultados observados como: refrigeradores em bom estado de conservação (80\%), lixeiras com tampa e sacos plásticos resistentes (100\%) e piso em cor clara, em bom estado de conservação, resistente e antiderrapante (70\%) (Tabela 2). 
Tabela 2. Avaliação higiênico-sanitária do manipulador e do ambiente de trabalho em estabelecimentos que comercializam carne moída e quibe cru na cidade de Presidente Prudente-SP.

\begin{tabular}{|c|c|c|c|c|}
\hline & \multicolumn{2}{|c|}{ SIM } & \multicolumn{2}{|c|}{ NÃO } \\
\hline & $\mathbf{N}$ & $\%$ & $\mathbf{N}$ & $\%$ \\
\hline $\begin{array}{l}\text { Piso de cor clara, em bom estado de conservação, resistente e } \\
\text { antiderrapante. }\end{array}$ & 7 & 70 & 3 & 30 \\
\hline $\begin{array}{l}\text { Mesas, armários, bancadas, equipamentos ou utensílios de madeira, } \\
\text { somente em inox. }\end{array}$ & 5 & 50 & 5 & 50 \\
\hline $\begin{array}{l}\text { Os funcionários usam jaleco ou camiseta, calça, avental, sapato fechado, } \\
\text { touca, gorro ou boné (que seja parte do uniforme de trabalho e de cor } \\
\text { branca); se usar boné mantiver os cabelos curtos e limpos. }\end{array}$ & 1 & 10 & 9 & 90 \\
\hline Os sanitários dos funcionários estão dentro da área de comercialização. & 1 & 10 & 9 & 90 \\
\hline Há presença de animais (cães, gatos, ratos) e insetos (moscas, baratas). & 5 & 50 & 5 & 50 \\
\hline $\begin{array}{l}\text { O lixo está acondicionado em baldes com tampa e sacos plásticos } \\
\text { resistentes. }\end{array}$ & 10 & 100 & 0 & 00 \\
\hline Os refrigeradores estão bem conservados. & 8 & 80 & 2 & 20 \\
\hline $\begin{array}{l}\text { Os funcionários possuem barba ou bigode? Do contrário, deverão usar } \\
\text { máscaras. Não podem usar brincos, pulseiras, colares, relógios ou outros } \\
\text { adornos. Manter as unhas curtas e limpas, sem esmalte ou base. }\end{array}$ & 0 & 00 & 10 & 100 \\
\hline Há caixas de papelão expostas na unidade. & 2 & 20 & 8 & 80 \\
\hline Os utensílios devem estar limpos, em bom estado de conservação. & 1 & 10 & 9 & 90 \\
\hline
\end{tabular}

\section{DISCUSSÃO}

A ocorrência de Doenças Transmitidas por Alimentos - DTA vem aumentando de modo significativo em nível mundial. As DTA's podem ser ocasionadas por mais de 250 tipos de bactérias, fungos ou vírus ${ }^{15}$. De acordo com dados divulgados pela Secretaria de Vigilância em Saúde, do Ministério da Saúde, entre os anos de 2000 e 2011, no Brasil, foram notificados 8.663 surtos de doenças veiculadas a alimentos, com 163.425 pessoas doentes e 112 óbitos. Muitos desses patógenos são transferidos para os alimentos devido à manipulação e preparação de inadequada ${ }^{16}$.

Coliformes totais são encontrados normalmente no ambiente e podem ser destruídos com certa facilidade pelo calor. Sua contagem pode ser útil em testes de monitorização de contaminações pósprocessamento $^{17}$. As contagens de coliformes totais encontradas neste trabalho demonstraram que $60 \%$ das amostras de carne moída apresentaram valores máximos de contagem
$(>100 \mathrm{NMP} / \mathrm{g})$, enquanto que $\mathrm{o}$ quibe cru apresentou apenas $6,66 \%$ apresentaram valores acima de $100 \mathrm{NMP} / \mathrm{g}$.

Os coliformes termotolerantes crescem, produzem ácidos e gás em temperaturas entre $44-46^{\circ} \mathrm{C}$. A presença destes coliformes indica as condições higiênicas de um alimento e provável presença de entero-patógenos. Além disso, é desejável determinar a incidência de $E$. coli numa população de coliformes, pois ela é o melhor indicador de contaminação fecal entre outros gêneros deste grupo $^{18}$. A RDC 12 de 2001 estabelece um limite de $5 \times 10^{3} \mathrm{UFC} / \mathrm{g}$ para coliformes termotolerantes para a carne moída. No presente trabalho foi determinado coliforme termotolerantes em amostras de carne moída e quibe cru. Tanto na carne moída quanto no quibe cru foi observado 6 amostras com valores abaixo do limite de deteç̧ão do método. Entretanto, 18 amostras apresentaram a presença de coliforme termotolerante e em uma delas o resultado encontrado foi de $100 \mathrm{NMP} / \mathrm{g}$, resultado superior ao estabelecidos pela legislação. 
Damer et al. ${ }^{6}$ avaliaram carne moída no Noroeste do Rio Grande do Sul. Foram analisadas 14 amostras de carne moída, todas contaminadas por coliformes totais e termotolerantes, indicando precárias condições de higiene no processamento. Alves et al. ${ }^{19}$ avaliaram a qualidade microbiológica de carne moída comercializada em Terezina-PI e observaram que das 30 amostras analisadas 15\% apresentaram contagens fora dos parâmetros da legislação para análise de coliforme termotolerante. Fossati ${ }^{20}$ avaliaram a qualidade microbiológica de quibe cru em cinco restaurantes árabes em Porto Alegre/RS e observaram que todas as amostras estavam em conformidade com a RDC 12 de 2001.

Apesar do quibe cru ser mais manipulado e ter acréscimo de outros ingredientes como farinha, ervas e condimentos não foi observado uma relação direta com o nível de contaminação e estas características, uma vez que as contagens de aeróbios mesofilos, bolores e leveduras foram relativamente semelhante aos valores encontrados para a carne moída, assim sendo, foi observado que mesmo o quibe cru ter passado por técnicas de preparo, os valores de aeróbios mesófilos, bolores e leveduras não houve grandes diferenças, em relação aos coliformes totais, foi observado que as amostras de carne moída, apresentaram um maior nível de contaminação em relação ao quibe. Para a presença de coliformes totais o nível de contaminação foi relativamente menor para ambos produtos alimentícios numa visão geral. Entretanto, vale ressaltar que produtos cárneos consumidos crus são considerados alimentos de alto risco epidemiológico e as características intrínsecas desses produtos favorecem o desenvolvimento de diversas espécies de bactérias patogênicas ${ }^{21}$.Isto pode ocorrer em função da utilização de carne contaminada para o preparo ou pela manipulação inadequada durante 0 preparo.

As altas contagens encontradas tanto nas amostras de quibe cru quanto de carne moída podem estar relacionadas provavelmente com à refrigeração inadequada. Além disso, o processo de moagem, pelo qual a carne moída passa, favorece a contaminação por microrganismos, pois aumenta a superfície de contato e proporciona a incorporação de resíduos de moagens anteriores. Deve ser dado também devido atenção ao maquinário e demais utensílios usados muitas vezes não são devidamente higienizados o que pode possibilitar novas contaminações e também aos manipuladores, pois representam um dos principais veículos de contaminação da carne ${ }^{19}$.

A qualidade da matéria-prima, a arquitetura dos equipamentos e das instalações, as condições higiênicas do ambiente de trabalho, as técnicas de manipulação dos alimentos, a saúde dos funcionários são fatores importantes a serem considerados na produção de alimentos seguros e de qualidade ${ }^{22}$. Os resultados obtidos neste estudo demonstram a necessidade da implementação e monitorização da aplicação das Boas Práticas de Fabricação nestes estabelecimentos a fim de garantir as condições higiênico-sanitárias.

Outros estudos também demonstraram a não conformidade em relação a condições higiênicas dos funcionários e estabelecimento. Poerner et al. ${ }^{22}$ avaliaram conformidades de cinco principais itens por meio da aplicação da lista de verificação nos serviços de alimentação. Segundo aqueles autores, requisitos de higiene dos estabelecimentos apresentaram $64 \%$ de conformidade e o item asseio pessoal dos manipuladores constatou-se $86 \%$ de não conformidades principalmente devido a presença de, por exemplo, manipuladores com adornos como anéis e brincos, unhas compridas e lesões visíveis nos dedos. Souza et al. ${ }^{23}$ avaliaram as condições higiênico-sanitárias de uma UAN hoteleira de Timóteo (MG) por meio de um checklist contendo avaliação para Boas Práticas em Serviços de Alimentação. A partir da aplicação do checklist, levantou-se a quantidade de itens adequados, inadequados e não aplicáveis a UAN hoteleira. Os itens contidos no checklist totalizam 182, sendo que 117 foram considerados adequados e 37 inadequados.

0 controle de qualidade no armazenamento, produção e no preparo de alimentos é muito importante uma vez que garantem qualidade na distribuição e segurança higiênico-sanitária dos produtos. Desta maneira, devem-se estabelecer as ações corretivas constantemente, mantendo o acompanhamento das atividades de higienização mesmo que se tenha um ótimo nível de capacitação entre os colaboradores para que haja um controle higiênico-sanitário satisfatório ${ }^{24}$.

Com os dados obtidos por meio das análises microbiológicas quando associados com as condições higiênico-sanitárias dos estabelecimentos e funcionários, é possível 
observar uma relação com os níveis de contaminação, uma vez que em todos os estabelecimentos havia algum ponto crítico inadequado e/ou alguma não conformidade, ou seja, $100 \%$ dos estabelecimentos apresentavam algum parâmetro inadequado, além de conter algum nível de contaminação. Isto fica mais claro quando associamos os estabelecimentos $\mathrm{A}$ tanto da carne moída, quanto do quibe cru, apresentaram altos níveis de contaminação para aeróbios mesofilos e coliformes totais, além do estabelecimento $D$ e $E$, estando com aeróbios, bolores e leveduras e coliformes totais elevados, mostrando que houve manuseio inadequado da carne. Para o quibe cru, é possível observar que o estabelecimento $F$ apresentou maiores precariedades na sua manipulação.

\section{CONCLUSÃO}

Os resultados obtidos com a análise microbiológica e o levantamento das condições higiênico-sanitárias dos estabelecimentos e funcionários despertam uma grande preocupação em relação aos riscos para a saúde do consumidor uma vez que algumas amostras demonstram altas contagens de microrganismos indicadores. A adoção de práticas adequadas de armazenamento e manipulação de alimentos, incluindo a correta higienização de mãos e superfícies podem são importantes na redução dos riscos gerados. Portanto, a educação continuada e o treinamento dos funcionários e manipuladores pode ser uma estratégia útil na redução das contaminações uma vez que este pode ser um ponto crítico durante 0 processamento do alimento. Além disso, é necessária uma maior fiscalização e monitorização dos estabelecimentos e dos produtos para garantia da segurança alimentar.

\section{AGRADECIMENTOS}

Os autores agradecem o apoio financeiro fornecido pela UNOESTE processo $n^{\circ} 3624$.

\section{DECLARAÇÃO DE CONFLITO DE INTERESSE}

Os autores declaram não haver qualquer conflito de interesse que possa interferir na imparcialidade deste trabalho científico.

\section{REFERENCIAS}

1. Brasil. Agencia nacional de vigilância sanitária. Doença Transmitida por Alimento (DTA). Santa Cararina. Acesso em: 23 dezembro 2018. Disponível http://www.vigilanciasanitaria.sc.gov.br/index.ph p/inspecao-de-produtos-eservicos-desaude/alimentos/91-area-de-atuacao/inspecaode-produtos-eservicos-de-saude/alimentos/415doenca-transmitida-por-alimento-dta

2. ABIEC - Associação Brasileira das Indústrias Exportadoras de Carne. Acesso em: 6 novembro 2018. Disponível em: http://www.abiec.com.br/noticia.asp?id=1378\#.v j5cwnkrqdu.

3. Medeiros AM. Análise dos Parâmetros Microbiológicos da Carne Bovina Moída in natura Comercializada na Mesorregião do Agreste Paraibano. Paraíba: Universidade Federal da Paraíba, 2017.

4. Ferreira SR, Simm ME. Análise microbiológica da carne moída de um açougue da região central do município de Pará de Minas/MG. SynThesis Rev Digital FAPAM, 2012;3:37-61.

5. Rodrigues AA, Sousa WL, Pinheiro REE, Carvalho APDLS. Aspectos higiênico-sanitários de estabelecimentos comercializadores de carnes no município de Bom Jesus-PI. Rev Bras Hig Sanid Animal. 2017;11:94-103.

6. Damer SRJ, Dill RE, Gusmão AA, Moresco TR. Contaminação de carne bovina moída por Escherichia coli e Salmonela spp. Rev Contexto Saúde. 2014;14(26):20-7. DOI: https://doi.org/10.21527/2176-7114.2014.26.20$\underline{27}$.

7. Bergamini $A M M$, Reche SHC, Oliveira CC, Zambini PH, Oliveira MA. Relato de surtos alimentares de origem bacteriana. Bol Inst Adolfo Lutz. 2013;23(1):16-7.

8. Filho MAR, Souza KJ, Lima LCF. Crises de segurança do alimento e a demanda por carnes no Brasil. Rev Econ Social Rural. 2016;54(3):45982. DOI: http://dx.doi.org/10.1590/123456781806-94790540304.

9. Silva LCG. Avaliação higiênico-sanitária e microbiológica de alface (lactuca sativa) comercializada em feira livre de Francisco Beltrão- PR. [Monografia]. Francisco Beltrão: Universidade Tecnológica Federal do Paraná UTFPR, 2015. 
10. Silveira CO, Silveira RO, Da cunha abreu C, Ritter MA. Abate clandestino: um risco para saúde pública. Anais V SIMPAC. 2013;5(1):133-8.

11. Brasil. Resolução RDC ANVISA/MS n.o 12, de 2 de janeiro de 2001. Regulamento Técnico sobre os Padrões Microbiológicos para Alimentos. Diário Oficial da União. Brasília, DF.

12. APHA - American Public Health Association. Compendium of methods for the microbiological examination of foods. 4.ed. Washington; 2001.

13. Food and drug administration FDA. Bacteriological analytical manual. 7th end AOAC International, Arlington: Virginia; 2002.

14. Brasil. Departamento vigilância sanitária. Lista de adequações para açougues fornecida pela vigilância sanitária de Santa Maria da Vitória Acesso em: 11 novembro 2018. Disponível em: http://www.mp.go.gov.br/portalweb/hp/4/docs/list a_de_adequacpes_para_acougues.pdf

15. Brasil. Portal da saúde. Acesso em: 30 de novembro de 2017. Disponível em: http://portalsaude.saude.gov.br/index.php/oministerio/principal/secretarias/svs/doencastransmitidas-por-alimentos-dta.

16. Oliveira MFAM. Doenças de origem alimentar. [Monografia]. São Paulo: Universidade Estadual de São Paulo, 2013.

17. Forsythe, Stephen J. Microbiologia da segurança alimentar. 2.ed. Porto Alegre: Artmed; 2002.

18. Franco BDGM, Landgraf M. Microbiologia dos alimentos. 3.ed. São Paulo: Ed. Atheneu; 2005.

19. Alves VC, Filho FCC, Rios FPB, Lima CE, Keller KM, Murtori MCS. Coliformes e Salmonellaspp em carne moída comercializada em Teresina, PI. Rev Bras Med Vet. 2011;33(1):32-6.

20. Fossati AAN. Avaliação da qualidade microbiológica de quibes crus preparados em restaurantes especializados em culinária árabe. [Monografia]. Porto Alegre: Universidade Federal do Rio Grande do Sul, 2011.

21. Braga HF, Ferreira IM. Quibe cru: qualidade sanitária e perigo à saúde. Rev Bras Pesq Saúde.
2013;15(4):123-9.

https://doi.org/10.21722/rbps.v15i4.7609

22. Poerner S, Rodrigues E, Palhano AL, Fiorentini AM. Avaliação das condições higiênico sanitárias em uma unidade de alimentação e nutrição hoteleira, Timóteo-MG. Rev Inst Adolfo Lutz. 2009;68(3):399-405.

23. Souza $\mathrm{CH}$, Sathler J, Jorge MN, Horst RFM. Avaliação das condições higiênico sanitárias em uma unidade de alimentação e nutrição hoteleira, na cidade de Timóteo-MG. Rev Digital Nutr. 2009;3(4):312-29.

24. Andreotti A, Blernoni FH, Paroschi VHB, Panza SGA. Importância do treinamento para manipuladores de alimentos em relação à higiene pessoal. Rev Inic Cient Cesumar. 2003;5(1):29-33. 